\title{
Intersetorialidade nas políticas públicas de esporte e lazer: uma análise do Programa Campeões de Futuro'
}

\author{
Carlos Nazareno Ferreira Borges ${ }^{2}$ \\ Marcelo de Souza Marques ${ }^{3}$
}

\section{Resumo}

O objetivo deste artigo é analisar os limites e as potencialidades do "Programa Campeões de Futuro" (PCF) enquanto uma política pública intersetorial de esporte educativo. Para tanto, analisamos as perspectivas de intersetorialidade, descentralização e democracia na gestão, com enfoque na participação da sociedade civil, tendo como base de análise documentos colhidos na Secretaria de Estado de Esporte e Lazer do Espírito Santo (Sesport) e em seu website, bem como entrevistas com a coodernação do PCF. Os resultados evidenciam que a concepção de esporte no PCF é diferenciada entre a prescrição e a implementação. Da mesma forma, encontramos na prescrição boa possibilidade de articulação entre os entes conveniados, características de intersetorialidade, mas não encontramos evidências de ocorrências na implementação.

Palavras-chave: Políticas Públicas. Esporte. Lazer. Intersetorialidade. Participação.

\section{Introdução}

Nas últimas décadas, observamos uma nova onda de áreas a serem contempladas e estrategicamente utilizadas pelo Estado no momento de criar e

I O presente trabalho é resultado da pesquisa "Relações Intersetoriais nas Políticas Públicas de Esporte e Lazer: Os Convênios Entre Governo do Estado e Municípios no Espírito Santo", do Centro de Estudos em Sociologia das Práticas Corporais e Estudos Olímpicos da Universidade Federal do Espírito Santo (CESPCEO/UFES) e financiada pela Fundação de Amparo à Pesquisa do Espírito Santo (FAPES).

2 Docente associado I da Universidade Federal do Espírito Santo no Programa de Pós-Graduação em Educação Física (PPGEF) e no Programa de Pós-Graduação em Ciências Sociais (PPGCSO). Doutor em Educação Física pela Universidade Gama Filho, Bacharel em Ciências Sociais pela Universidade Federal do Espírito Santo e Pós-doutorado em Memória Social pela Universidade Federal do Estado do Rio de Janeiro.

E-mail: carlos.nazareno@pq.cnpq.br.

3 Mestrando em Ciência Política pela Universidade Federal de Pelotas (PPGCPOL-UFPel). Bolsista CAPES - Coordenação de Aperfeiçoamento de Pessoal de Nível Superior. E-mail: marcelo.marques.cso@gmail.com. 
implementar políticas públicas, e dentre estas novas áreas se destacam o esporte e o lazer. A Associação entre esses dois objetos é mais recente no Brasil, tanto no campo de intervenção, quanto na produção de conhecimentos, no entanto, o esporte tem sido objeto das políticas públicas desde a década de 40 do século passado, conforme mostram os estudos de Manháes (2002).

Ainda que existam informaçóes relacionadas à aproximação estreita entre Estado e as instituiçóes esportivas ao longo dessa história recente do Brasil desde o período mencionado, esporte e lazer passaram a ser tomados como direitos constitucionais a partir da Constituição Federal de 1988 (CF/88). Especificamente, o esporte (sob a denominação de Desporto) é contemplado no artigo 217 da Constituição Federal (BRASIL, 1998), e este regulamenta todas as dimensóes de prática, denominadas de: desporto de alto rendimento, desporto educacional e desporto de participação (não profissional).

O lazer se constitui como direito social, conforme o artigo $6^{\circ}$ da Carta Constitucional, o qual contém em seus pressupostos teóricos e práticos, também, a dimensão do esporte (recreativo). Dessa forma, tanto na dimensão vivencial recreativa, quanto na dimensão contemplativa do lazer, o esporte se constituiu como direito (social) e passou a gerar demandas na agenda política. Além disso, no $₫ 3^{\circ}$ do mencionado artigo $217^{\circ}$ da $\mathrm{CF} / 88$, lê-se: "O Poder Público incentivará o lazer, como forma de promoção social". A nosso ver, esse parágrafo, associado ao artigo $6^{\circ}$, caracteriza a aproximaçáo entre os dois objetos na perspectiva constitucional, e nos permite a discussão de como o lazer se aproxima do esporte em todas as suas dimensóes.

Constituídos como direitos, esporte e lazer passaram, entáo, a integrar a agenda pública, implicando a implementação de Políticas Públicas de Esporte e Lazer (PPEL's).

No entanto, seguindo a tradição de prioridades entre as necessidades humanas, as PPEL's são muitas vezes propostas e efetivadas conjuntamente com políticas de outros setores da gestáo, associadas a outros direitos (como saúde e educação). Em geral, as ações implementadas em conjunto adquiriram o caráter de intersetorialidade.

Além das parcerias em nível governamental entre secretarias, pastas e autarquias, voltamo-nos às possibilidades de intersetorialidade com outros setores, como as entidades da sociedade civil, no processo de implementação, elaboração e avaliação de PPEL's. 
O quadro até aqui exposto também é reproduzido no Espírito Santo. E, após desenvolvermos estudos na Secretaria de Estado de Esporte e Lazer (Sesport), deparamo-nos com somente dois programas com potencialidades de intersetorialidade, o "Programa Campo Bom de Bola" e o "Programa Campeóes de Futuro" (PCF). O primeiro se tratava mais de uma ação de transferência de recursos entre entes conveniados; por isso, optamos pelo segundo, uma vez que esse previa responsabilidades partilhadas dos entes conveniados na implementação da política.

O PCF, com 150 unidades espalhadas por todos os 78 municípios capi$x^{x a b a s}{ }^{5}$, caracteriza-se como iniciativa de educaçáo pelo esporte (esporte educacional), o que implicará em tratarmos melhor a dimensão educacional no decorrer do trabalho, à luz da discussão teórica sobre o esporte, tomando-o a partir da tríade esporte de rendimento, educacional e participativo.

Tendo em vista as possibilidades e os limites do esporte como elemento de interaçáo e inclusão social ${ }^{6}$, estabelecemos o objetivo de analisar os limites e as potencialidades do "Programa Campeóes de Futuro (PCF)" enquanto uma política pública intersetorial de esporte educativo, entendendo, conforme poderemos demonstrar, a relaçáo estreita entre os conceitos de intersetorialidade, descentralização e participaçáo da sociedade civil como pressuposto de uma gestão democrática e moderna. Nesse sentido, pensamos em dirigir a sequência das seçóes pelas seguintes questôes: que concepção(óes) de esporte parece $(\mathrm{m})$ estar inserida(s) nos documentos referentes ao PCF? Qual a perspectiva de o programa se constituir enquanto política pública? Que perspectivas existem de o programa ser implementado com características de intersetorialidade? Como pode o PCF se constituir como promotor de inclusão social e da construçáo da cidadania a partir do esporte educacional?

40 "Programa Campo Bom de Bola" (PCB) possibilita o financiamento de equipamentos esportivos especificos para a prática de futebol nos municípios do Estado. No entanto, não há previsão de implementação de programas de animação dos equipamentos sob a responsabilidade do governo do estado.

5 Capixaba é o termo utilizado para designar a naturalidade no estado do Espírito Santo. Cada convênio possui um determinado número de núcleos, visto que, em cada núcleo, são atendidas 200 crianças entre 7 e 17 anos de idade. Ainda segundo a apresentação do PCF no site da Secretaria, os núcleos promovem o aprendizado de diversas modalidades esportivas, entre as quais são citadas: voleibol, atletismo, ginástica rítmica, futebol de areia, futsal, futebol de campo, basquete, handebol, judô, bodyboarding, natação, capoeira e xadrez. Disponivel em: <http://www.sesport.es.gou.br/>.

6 Como têm trabalhado alguns autores, como Mascarenhas (2004), Rittner (2009), Azevedo (2009), Freitas (2009), Marinho (2010). 
Para tanto, valemo-nos de levantamento das açóes efetivas de esporte e lazer realizadas pela Sesport no período de 2005 a 2010 em caráter intersetorial com os municípios do Estado. As fontes de pesquisa foram os documentos solicitados à Sesport (e também capturados no site da secretaria), referentes às açôes realizadas no período, cujos convênios com os municípios apresentassem evidente participação de ambas as partes no processo de desenvolvimento das políticas. Posteriormente, em função dos objetivos do estudo, concentramos a busca aos documentos relacionados ao PCF. Os principais documentos encontrados foram: o projeto (prescrição) orientador do Programa; o Protocolo de Intençóes para estabelecimento de convênio entre Sesport e Prefeituras (Modelo); Relatórios de Avaliação do Espaço Físico (realizados pela Sesport quando em visita aos municípios); Relatórios de Avaliação Mensal (preenchidos por professores das entidades e enviados à Sesport). Todas as fontes coletadas constituíram-se em material trabalhado, o qual foi interpretado pela técnica de análise documental proposta por Richardson e Peres (1999).

Na primeira seção, apresentaremos os objetivos do PCF que instigaram nossa pesquisa, analisando-os à luz da literatura que discute as possibilidades e os limites dos esportes como elementos de interação e inclusão social, bem como refletiremos sobre as dimensóes de esporte presentes no PCF. No item 2, "O PCF e o cenário local", nossos esforços se concentrarão para situarmos o PCF no cenário desenvolvimentista da política capixaba do período retratado, expresso no documento "ES 2025". Na sequência, daremos continuidade às nossas análises, e, a partir dos dados levantados, discutiremos PCF quanto à sua dimensão esportiva e intersetorial. Por fim, apresentaremos nossas consideraçóes.

\section{Conhecendo o programa campeões de futuro}

O PCF tem como justificativa de sua açáo a promoçáo do atendimento às pessoas em situação de risco social "[...] apresentando novos interesses e oportunidades, além de um entendimento de seu papel como cidadão" (SECRETARIA DE ESTADO DE ESPORTE E LAZER, [s. d.] [a], [s. p.]) ${ }^{7}$. Seus objetivos giram em torno da promoçáo - a partir da prática esportiva -

7 Trata-se do documento orientador do programa (projeto escrito). Nesse texto, não referenciaremos o ano de publicação nem a página por desconhecermos essas informações. 
da proteção integral de seus usuários (crianças, adolescentes e jovens), como percebemos nos objetivos destacados do Programa:

Promover a partir da prática do esporte e do lazer, a proteção integral de crianças, adolescentes e jovens, a sua inserção na comunidade e a formação de cidadãos conscientes de seus deveres, direitos e atuantes na sociedade.

Desenvolver estratégias de ações pedagógicas que irão referenciar nas condições concretas dos alunos com predominância de procedimentos centrados na iniciativa do aluno, propondo desafios e visando à solução de problemas, apresentando atividades em diferentes níveis de desempenho, de acordo com as experiências das técnicas e instrumentos a serem empregados e com diálogo constante entre professor $x$ aluno.

Propor metodologias de trabalho que integrem os conteúdos, as visões de que o processo educacional é permanente. Fundamentando-se em seis princípios socioeducativos, que norteiam as ações pedagógicas, utilizando-se durante as atividades práticas, de técnicas que propiciem: o saber coletivo (coeducação), a capacidade de organização em grupo (cooperação), a reflexão crítica (emancipação): posicionando o educando como sujeito (totalidade), agente de sua aprendizagem (participação), a partir da realidade na qual está inserido (regionalismo). (SECRETARIA DE ESTADO DE ESPORTE E LAZER, [s. d.] [a], [s. p.]).

No entanto, como destacam Melo (2005), Rittner (2009), Azevedo (2009) e Marinho (2010), o esporte por si só não consegue resolver os problemas sociais. O esporte não é, em si, um fator de inclusão social. É um erro tratá-lo como a soluçáo de problemas que, na verdade, demandam açóes políticas interligadas a outras áreas e não simplesmente ao desenvolvimento de programas esportivos (MELO, 2005). Nesse sentido, Freitas (2009) afirma:

A parolagem sobre as políticas públicas de esporte à inclusão social de crianças e de adolescentes não diz onde serão incluídas [...], nem por que se encontram excluídas e nem quem as excluiu. Os esportes não são antídoto ao processo de exclusão histórica inerente ao capitalismo e nem jamais serviu de alavanca para reverter quadros sociais de miséria, desemprego e violência urbana e rural. É enganoso discursar sobre a inclusão social mantendo às escuras as causas da exclusão. Os esportes como suposto fator de inclusão social é discurso "esquerdista" verossímil à hipócrita fala reacionária da direita sobre a humanização das favelas. (p. 157).

A busca pela inclusão social dá-se, portanto, para além do uso dos esportes, o que não significa afirmar que o esporte não tenha sua relevância na busca por uma nova ordem social, mas que a questão ultrapassa as visóes salvacionistas e funcionalistas, normalmente atribuídas ao esporte. 
Segundo Marcellino (2001), essa concepção deturpada de inclusão social, por meio do esporte, que no nosso caso está impressa no PCF, também é problemática no caso de programas especificamente voltados para o lazer. Quase sempre a ideia de lazer está condicionada aos jogos e às brincadeiras, realizados frequentemente de forma utilitária. Esse tipo de concepção é contrário ao lazer pensado a partir das categorias tempo e atitude, pelas quais se concebe o lazer como a vivência da cultura no tempo disponível, por meio de diversos interesses buscados pelo indivíduo de forma livre e prazerosa, mas que possibilitam o desenvolvimento social e pessoal.

Essas concepçóes muitas vezes se encontram ocultas, outras vezes são expostas, mas, pode-se inferir, a partir da construção e execução de determinadas políticas públicas, uma visão funcionalista e conservadora, na qual acabam instrumentalizando os participantes para a vida social dentro do modo de produção econômico vigente.

O PCF é um programa de esporte que não é declarado como um programa de lazer; por isso não, nos prenderemos em discutir profundamente os estudos do lazer. Contudo, poderemos encontrar mais adiante a presença de um discurso híbrido de uso do esporte perspectivado também no lazer. Embora o esporte se constitua como uma possibilidade de ocupaçáo do tempo no lazer, sendo o PCF um programa dirigido pela intencionalidade da prática esportiva, não necessariamente essa prática terá a dimensáo do lazer, ou talvez a mantenha com aquela concepção de um lúdico utilitário.

Enquanto um programa declarado de esporte, como percebemos em sua justificativa ao afirmar que pretende "[...] promover o desenvolvimento de crianças, adolescentes e jovens, priorizando o atendimento aos carentes, por meio de práticas esportivas variadas e integradas [...]" (SECRETARIA DE ESTADO DE ESPORTE E LAZER, [s. d.] [a], [s. p.], grifo nosso), o PCF está sujeito à discussão das "inadequaçóes" conceptuais sobre as dimensôes do esporte inseridas nas políticas públicas.

Como demonstrou Tubino (2011), o esporte possui três dimensóes: educacional, participativa e performática (ou de rendimento) ${ }^{8}$. O esporte

8 Como vimos, essa classificação está presente também no texto constitucional. No entanto, tal classificação se deve à tradição na área da Educação Física, segundo Veronez (2005), promovida desde o Manifesto sobre o esporte, do Cieps (CONSEIL INTERNATIONAL POUR L'ÉDDUCATION PHYSIQUE ET LE SPORT), em 1964. 
educacional é aquele praticado preponderantemente nas escolas, embora possa ser desenvolvido em outros ambientes, desde que seja com caráter educativo, objetivando a democratizaçáo das práticas esportivas e explorando as potencialidades do esporte enquanto prática pedagógica e elemento de inclusão social. $\mathrm{O}$ esporte participativo vincula-se à prática pela prática, com caráter de prazer lúdico, visando ao descanso, à diversão e ao desenvolvimento pessoal dos indivíduos em seu tempo livre (disponível) - é nesse sentido que encontramos a dimensáo de esporte perspectivado, também, no lazer, como apontando por Marcellino (2001). Já o esporte de rendimento se caracteriza por normas rígidas e preestabelecidas; logo, é uma prática que induz à competitividade.

Embora esse modelo ideal de esportes esteja presente em textos jurídicos e em documentos institucionais e, de certa forma, auxiliar-nos no estudo, ele náo pode ser analisado tomando cada elemento isoladamente. Como argumenta Bracht (1997), corroborado por Oliveira (2005), qualquer prática esportiva possui uma dimensão educativa, bem como o esporte educativo pode estar ligado ao esporte participativo ou mesmo ao de rendimento. Nesse caso, há o destaque para uma dimensão moral do esporte, tomado eminentemente como educação, que deveria perpassar todas as suas formas de manifestação.

Dando outra contribuição, Melo (2005) argumenta que o esporte de rendimento, marcado pela lógica do mercado, pela espetacularizaçáo, está a se tornar o modelo para a maioria das práticas esportivas nas sociedades capitalistas, tanto na dimensão participativa quanto na educacional. Esse pensamento é, também, defendido por Oliveira (2005), ao discutir sobre o esporte educacional.

O esporte praticado na escola, ou organizado a partir do vínculo escolar, é regido pelo esporte de rendimento como modelo, mas, no tocante aos pontos de inter-relação, assume o mesmo lugar do esporte como atividade de lazer, ou seja, também é celeiro de atletas, também forma os consumidores do esporte e compartilha das instalações que servem ao esporte-espetáculo. (OLIVEIRA, 2005, p. 96).

Essa discussão nos ajuda a refletir sobre o PCF, um projeto que se pretende caracterizar como uma intervenção no campo do esporte, perspectivando-se como ferramenta educacional, mas que precisa ser observado não somente a partir de uma concepção mais holística de esporte, como também no panorama de políticas públicas do Governo do Estado, como apresentaremos a seguir. 


\section{PCF e o cenário estadual}

Para começar a discutir a caracterização do PCF como uma PPEL, é precisamos lembrar que o Estado do Espírito Santo, inserido em perspectiva hegemônica nas entidades federativas do Brasil, mantém suas iniciativas de gestão pautadas no modelo gerencial, conforme apontado por Paula (2005), porque conduz a gestáo pautada em uma concepção de Estado também hegemônica no Brasil, orientada pelos preceitos neoliberais (MELO, 2005). No país, esses preceitos condizem com a ideia de desenvolvimento, tendo como parâmetro países "desenvolvidos".

Nesse sentido, para a fim de promover suas intencionalidades orientadas para a ideia de desenvolvimento, o Espírito Santo é gestado pelo planejamento estratégico, o qual foi publicado, no ano de 2006, em um documento de 11 volumes, denominado de "Plano de Desenvolvimento Espírito Santo 2025" e conhecido, também, como ES-2025. Nesse documento, encontramos os eixos norteadores do desenvolvimento pretendido, quais sejam: 1) Desenvolvimento do capital humano referenciado por padrôes internacionais de excelência; 2) Erradicação da pobreza e redução das desigualdades para ampla inclusão social; 3) Diversificação econômica, agregação de valor à produção e adensamento das cadeias produtivas; e 4) Desenvolvimento do capital social e da qualidade e robustez das instituiçóes capixabas (GOVERNO DO ESPÍRITO SANTO, 2006). Nesse sentido, todas as iniciativas do Estado deveriam apontar para o almejado desenvolvimento, inscritas em um ou mais desses eixos.

Pelos motivos mencionados, as discussões das políticas públicas de interface entre esporte e lazer no Estado do Espírito Santo aparecem no documento final do Plano ES-2025 como sendo de grande relevância para o desenvolvimento político regional. $\mathrm{O}$ documento aponta para a busca de debate acerca da intersetorialidade do esporte e lazer com outros setores que pretendem atender a direitos sociais e/ou interesses de caráter econômico local, entre os quais o da educação, da saúde, da cultura, do turismo, segurança (GOVERNO DO ESPÍRITO SANTO, 2006). Fica compreensível, portanto, o surgimento do PCF no ano de 2007, constituindo-se como uma das políticas inseridas no grande plano de desenvolvimento do Estado.

Areias et al. (2012) identificaram, no plano ES-2025, quatro eixos norteadores para as açóes envolvendo o esporte que seriam, portanto, a pretensão 
do plano. $\mathrm{O}$ primeiro desses eixos norteadores refere-se à ideia do esporte como estratégia para o controle dos problemas relacionados à segurança pública ou ao controle da violência, por meio de projetos desenvolvidos para esse fim. Essa, como já sabemos, é uma ideia recorrente e tem sido tratada com reservas críticas por diversos autores no Brasil, como é o caso dos estudos de Mascarenhas (2004) e Melo (2005), entre outros.

No segundo eixo norteador, o Plano ES-2025 considera o esporte como meio de proporcionar a chamada "vida ativa", algo bastante interessante em tempos de aumento do número da população idosa, a qual precisa estar isenta da inatividade, das doenças hipocinéticas, e, assim, evitar problemas futuros de sobrecarga do sistema de saúde. Assim consideradas, muitas iniciativas com o uso do esporte, inclusive o PCF, podem ser alocadas na perspectiva de focalização criticada por Behring e Bochetti (2008), isto é, o processo de seleção dentro dos grupos sociais a quem as políticas sociais devem chegar - critérios de seleção excludente, focalizados/seletivos ${ }^{9}$.

No terceiro eixo, pensa-se o esporte como boa estratégia de desenvolvimento do turismo; nesse caso, tomado a partir de sua vinculação com as práticas corporais realizadas na natureza, considerada como uma perspectiva em grande desenvolvimento na atualidade. Marinho (2008) esteve discutindo a ideia de desenvolvimento que relaciona atividades junto à natureza aos avanços tecnológicos, o que implica, também, investimentos e lucros em termos de equipamentos e pessoal especializado, algo que obviamente interessa ao mercado. No caso do Espírito Santo, considera-se a perspectiva muito interessante, se considerada a sua característica geográfica com relação ao litoral e a montanhas potenciais reconhecidos para as práticas de atividades junto à natureza.

Por fim, o Plano ES-2025 considera o esporte uma boa estratégia de projeção do nome do Estado para o país e para o cenário internacional, o que implica também possibilidade de incremento da autoestima do cidadáo

9 A focalização/seletividade é apontada por Faleiros (1988, p. 28) como um fenômeno recorrente em finais do século XX, mas que ainda hoje é possivel encontrar. Segundo o autor, em países periféricos, como o Brasil, as políticas sociais não são de acesso universal. Caracterizam-se por ações "categoriais", "[...] isto é, que têm como alvo certas categorias específicas da população, como trabalhadores (seguros), crianças (alimentos, vacinas), desnutridos (distribuição de leite), certos tipos de doentes (hansenianos, por exemplo), através de programas criados a cada gestão governamental, segundo critérios clientelísticos e burocráticos". 
capixaba, uma vez que intensifica sentimentos de pertencimento e de identidade. Senos (1997) já havia acenado que estratégias são desenvolvidas no grupo social, sobretudo em idade escolar no ambiente escolar, para que a identidade social e sentido de pertença sejam desenvolvidos; e o documento de fundamentaçáo pedagógica para o PCF em nível nacional aponta o esporte como essa estratégia (OLIVEIRA; PERIM, 2008).

Em todas as suas perspectivas, ora mais ora menos evidente, o PCF representa uma iniciativa coerente com o plano ES -2025, seja a curto, médio, ou longo prazo. Não por menos, o PCF frequentemente está nos discursos de inclusão pelo esporte, como também na possibilidade de carreira no esporte, perspectivando mobilidade social.

Esse tipo de discurso se inscreve bem nas dimensóes internas e externas apontadas por Brohm citado por Oliveira (2005), para o qual o esporte possui, nas sociedades contemporâneas, funçôes sociopolíticas externas (diplomacia; "paz universal" pelo esporte etc.) e internas, tais como: integração/inclusáo social pelo esporte (estabilizaçáo do sistema capitalista); despolitizaçáo pelo esporte (ocupação do tempo livre dos cidadáos; esporte enquanto benefício concedido pelo Estado e não enquanto um direito conquistado); mantenedor da ordem pública e a colaboração entre as classes.

Talvez por haver uma concepçáo de esporte relacionada com as perspectivas do ES 2025, os gestores estaduais tendem a aproximar as concepçóes entre o esporte educacional e o esporte de rendimento quando se referem ao PCF e, ainda que o discurso da inclusão social permaneça, o discurso do rendimento é que projeta.

Em discurso proferido no dia 15 de setembro de 2010, o governador do estado, ao homenagear atletas capixabas vencedores nas Olimpíadas Escolares Brasileiras em matéria no diário oficial do estado ${ }^{10}$, enfatizou o apoio de seu governo ao esporte, sobretudo ao PCF, o que contribui para que os resultados no campo apareçam. Em outra ocasiáo, em publicaçáo no mesmo veículo no dia 30 de junho de 2010, quando na ocasiáo se destacava o sucesso de atletas capixabas em diversas competiçóes, também foi enfatizado que um aluno

10 Publicação no Diário oficial dos Poderes do Estado de 16 de setembro de 20 I0. Disponível em: <http://www. dio.es.gou.br/>. 
vinculado ao PCF, embora tivesse apenas 15 anos, já despontava em competiçóes de bodyboarding.

Portanto, um indicativo pelo menos já parece evidente: há dissonâncias entre o que encontramos nos discursos correntes e nas prescriçóes do PCF, assim como nas informaçóes do site da Sesport. As contradiçóes parecem mais evidentes quando analisamos os diferentes documentos utilizados para o acompanhamento do PCF quanto à tomada do esporte educacional como orientaçáo do Programa. Como veremos no próximo tópico, o PCF apresenta fortes elementos que o aproximam mais do esporte de rendimento, ainda que este seja declaradamente um programa de esporte educacional.

\section{Descobrindo as (in)coerências do PCF}

Neste tópico, trataremos de dois pontos específicos: a aproximação e o distanciamento do PCF das características que apontam teoricamente para um programa de esporte educacional e para a aproximação e o distanciamento da caracterização de uma ação intersetorial.

\section{I O PCF e sua dimensão esportiva}

Ao analisarmos os objetivos e a apresentação do Projeto Prescrito do PCF, percebemos o destaque conferido às dimensóes educativa e participativa do esporte.

Segundo se lê no documento do projeto, o esporte é entendido como "[...] fenômeno socioeducativo de potencial indiscutível na contribuição para a formação do indivíduo [...] para estreitar o elo entre o desporto e a educaçáo". Especificamente quanto ao destaque à dimensáo participativa, pode-se ler: "[...] tem como objetivo proporcionar na forma democrática o acesso ao esporte e lazer na elevaçáo do bem-estar da população como meta suprema e invariável na perspectiva da melhoria da qualidade de vida" (SECRETARIA DE ESTADO DE ESPORTE E LAZER, [s. d.] [a], [s. p.]).

O ponto de partida para começar a discutir as aproximaçóes ou náo do PCF à dimensáo de esporte educacional vem dos itens "piso, tamanho local e acesso ao local", presentes na Tabela 1, e que foram extraídos da "Ficha de avaliaçâo do espaço físico das práticas corporais - projetos sociais", elaborada pela Sesport. A partir desses itens, refletiremos sobre a concepção de esporte inserida no PCF. 


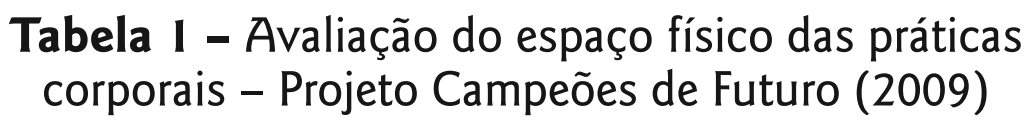

\begin{tabular}{|c|c|c|c|c|}
\hline \multirow[b]{2}{*}{ Estrutura } & \multicolumn{4}{|c|}{ Grau de satisfação } \\
\hline & $\begin{array}{c}\text { Muito } \\
\text { satisfatório }\end{array}$ & Satisfatório & $\begin{array}{c}\text { Pouco } \\
\text { satisfatório }\end{array}$ & Insatisatório \\
\hline Piso & 15 & 22 & 7 & - \\
\hline $\begin{array}{l}\text { Tamanho } \\
\text { local (13x|3) } \\
\text { / } 8 \text { m altura }\end{array}$ & 18 & 19 & 3 & 1 \\
\hline $\begin{array}{l}\text { Acesso ao } \\
\text { local }\end{array}$ & 11 & 26 & - & - \\
\hline Total & 44 & 67 & 10 & I \\
\hline
\end{tabular}

Fonte: Monitoramento do PCFII.

Ao nos voltarmos para os aspectos apresentados na Tabela 1, para analisarmos a concepçáo de esporte inserida no programa, percebemos que o conjunto dos itens evidencia a satisfação da coordenação geral com as instalaçôes. Ressaltamos que os documentos indicam instalaçôes que não seguem os parâmetros oficiais para a prática do esporte previstos nas regras das modalidades esportivas constantes no PCF. Portanto, as dimensóes do espaço físico não correspondem às exigidas para a prática esportiva de rendimento, embora fossem de responsabilidade dos municípios, como prevê o documento orientador do projeto.

De acordo com esse documento, cabe ao Estado coordenar e financiar o projeto, disponibilizando material esportivo, técnico, pedagógico, além de estagiários e curso de capacitação para os profissionais envolvidos. Aos municípios, cabe disponibilizar, adequadamente e com segurança, a prática do projeto; manter profissionais de Educação Física à disposição; envolver as

II Dos 45 relatórios preenchidos durante o ano de 2009, quatro não preencheram o item "Tamanho do local" (Conceição da Barra, Marechal Floriano, Mucuri e Mimoso do Sul); um não preencheu o item "Piso" (Guaçuí); oito não preencheram o item "Acesso ao local". Desses, um (Jaguaré) simplesmente não preencheu o referido item, o restante (um de Aracruz; um de São Mateus; dois de Cachoeira de Itapemerim; três de Santa Teresa) estão em outro modelo de Ficha de Avaliação utilizado pelo Projeto Campeões do Futuro, onde não consta o referido item. Desse modo, desconsideramos a avaliação do "Acesso ao local" nos Municípios citados, já os demais itens foram devidamente contabilizados. 
diferentes secretarias municipais no projeto (essa competência será retomada em destaque adiante); e, quando possível, disponibilizar lanches aos usuários do projeto e garantir a manutenção do espaço físico.

O fato de as instalaçóes serem de responsabilidade dos municípios e estas não estarem de acordo com as exigências para a prática esportiva de rendimento poderia indicar uma adequação dos aparelhos e, consequentemente, alteraçóes das regras oficiais para a prática do esporte educativo. No entanto, o documento dos estudos sobre o Perfil dos Municípios Brasileiros (IBGE, 2006), na seção de informaçóes básicas municipais - suplemento de esporte, publicado pelo IBGE em convênio com o Ministério do Esporte ${ }^{12}$ - já indicava a realidade da falta de equipamentos esportivos e espaços oficiais na maior parte das cidades do interior no Brasil em geral e no Espírito Santo em particular.

Bueno (2008) cita o Diagnóstico da Educação Física e do Desporto no Brasil, publicado por Lamartine Pereira da Costa em 1971; depois, cita os estudos de Bracht (1997); e, finalmente, mostra, por meio de dados de seu próprio estudo, que nada foi alterado em relaçáo ao modelo piramidal do esporte estabelecido historicamente no Brasil. Segundo esse modelo, o esporte de alto rendimento está no topo, seguido do esporte de participação e, na base, está o esporte escolar. $\mathrm{O}$ autor mostra que os investimentos em geral com a infraestrutura inclusive, seguem o fluxo piramidal de cima para baixo. Isso demonstra porque os municípios que conveniam com PCF possuem equipamentos ou Espaços esportivos muitas vezes adaptados e sem as medidas oficiais dos desportos, porque constantemente são concebidos para desporto escolar e de participação.

Apesar do descompasso apontado, o convênio cobra dos conveniados equipamentos "oficiais", certamente o que poderia aproximar a prática inicial aos interesses do esporte de alto rendimento, embora isso possa ser feito nos espaços e com o uso de equipamentos adaptados.

Portanto, como a existência de equipamentos em medidas oficiais ou não pode apontar para seu uso em diferentes dimensóes do esporte, o dado não parece apontar para uma aproximação da perspectiva de esporte educacional, e nossa suspeita se confirma na análise das Tabelas 2,3 e 4, que veremos adiante.

12 Disponivel em: <http://www.ibge.gou.br/home/estatistica/economia/perfilmunic/esporte2003/esporte2003.pdfs. 


\section{Tabela 2 - Avaliação Mensal das Aulas pelos Objetivos - Projeto Campeões de Futuro (2009)}

\begin{tabular}{lc}
\hline Objetivos das aulas & $\begin{array}{c}\text { Ocorrência de } \\
\text { indicadores }\end{array}$ \\
\hline Ensino de regras voltadas para situações de jogos & 10 \\
Ensino de fundamentos & 7 \\
Socialização e cooperação entre as crianças & 7 \\
Condição geral do indivíduo & 7 \\
Saúde, educação, cultura e formação cidadã pela prática do esporte e lazer & 2 \\
Motivar a prática esportiva & 2 \\
\hline
\end{tabular}

Fonte: Elaboração dos autores a partir dos relatórios mensais do PCF

Tabela 3 - Avaliação Mensal das Aulas pelos Indicadores de Acompanhamento na Execução - Projeto Campeões de Futuro (2009)

Avaliação das aulas ministradas

Ocorrência de indicadores

Interesse e dedicação no desenvolvimento das atividades 9

Comprometimento com as regras e fundamentos 4

Desenvolvimento da condição geral do indivíduo 2

Interação e cooperação entre as crianças

Baixo interesse e dedicação no desenvolvimento das atividades

Fonte: Elaboração dos autores a partir dos relatórios mensais do PCF

Tabela 4 - Avaliação Mensal das Aulas Considerando as Atividades

Extracurriculares - Projeto Campeões de Futuro (2009)

\section{Atividades extracurriculares}

Ocorrência de indicadores

Nenhuma atividade realizada 3

Brincadeiras lúdicas

Participação em competição/realização de competição

Ensino de regras por meio de filmes, internet e livros

Atividades que desenvolvam a interação e cooperação entre as crianças

Fonte: Elaboração dos autores a partir dos relatórios mensais do PCF 
As Tabelas 2, 3 e 4 foram elaboradas a partir dos planejamentos e relatórios mensais do PCF que nos foram disponibilizados. Quando cruzamos os elementos pedagógicos presentes nos planejamentos e relatórios (objetivos, métodos, avaliaçáo etc.), com os objetivos encontrados no documento orientador do projeto já mencionados nesse texto, observamos claramente uma desconexão entre o prescrito e o vivido.

A Tabela 2 refere-se aos "Objetivos das aulas", que normalmente são previstos nos planejamentos. Podemos perceber que os dois primeiros indicadores (Ensino de regras voltadas para situaçóes de jogos e Ensino de fundamentos) têm 17 ocorrências. Trata-se de indicadores que potencialmente se relacionam à prática esportiva de rendimento, caracterizada por normas rígidas, positivadas, cujo intuito é a formação de atletas. Se esse quantitativo for somado ao indicador "Condição geral do indivíduo", com sete ocorrências, e com uma grande possibilidade de ênfase nos aspectos biológicos, isto é, no condicionamento físico, a tendência de centralização na perspectiva do rendimento aumenta.

Quando observamos, na Tabela 2, a soma dos demais indicadores, que deveriam apontar mais para a perspectiva do esporte educacional e de participaçáo, vemos que a ocorrência é menor do que aqueles mencionados antes. Ou seja, a soma de três indicadores que sinalizam maior proximidade com o esporte educacional e participativo, apresentou ocorrência bem menor se comparada com a soma dos três indicadores que sinalizam aproximaçáo maior com a dimensão do esporte de rendimento.

Na Tabela 3, "Avaliação das aulas ministradas", apesar de grande abstenção no preenchimento do instrumento, vemos que o segundo indicador, "Comprometimento com as regras e fundamentos", com quatro ocorrências, é revelador. Se somado ao seguinte "Desenvolvimento da condição geral do indivíduo", com duas ocorrências, percebemos o quanto é importante, na avaliaçáo dos professores, a aprendizagem de elementos intrínsecos ao esporte enquanto tradição de competição. O contraste em relação ao indicador "Interação e cooperação entre as crianças", com uma ocorrência, é visível.

Se considerarmos, ainda, o destaque observado no indicador "Interesse e dedicação no desenvolvimento das atividades", disparado com nove ocorrências, poderemos inferir que muita atenção é dada à forma como as crianças do 
PCF assimilam a proposta de ensino do esporte enviesado pelos indicadores antes mencionados.

A Tabela 4, "Atividades extracurriculares", tem características mais singulares do que as tabelas anteriores. Podemos destacar os indicadores "Participação em competição/realização de competição" e "Ensino de regras por meio de filmes, internet e livros" como elementos diretamente relacionados à dimensão de esporte de rendimento, de formação de atletas.

Além das evidências de distanciamento da dimensão do esporte educacional a partir da "Avaliação Mensal das Aulas", podemos, igualmente, analisar os objetivos de "Socialização e cooperaçáo entre as crianças" (Tabela 2), os resultados obtidos (Tabela 3) e as atividades extracurriculares (Tabela 4) que contribuem para os objetivos almejados (Tabela 2).

Como podemos perceber na Tabela 2, a "Socialização e cooperação entre as crianças", que é um dos principais objetivos das aulas do PCF, com sete ocorrências, é um dos melhores indicadores apontados no ato de planejar. No entanto, na avaliação das aulas ministradas (Tabela 3), já com a denominação "Interação e cooperação entre as crianças", com apenas uma ocorrência, está entre os menores, ao lado do indicador "Baixo interesse e dedicação no desenvolvimento das atividades". Isto nos permite inferir que esse objetivo não foi alcançado - segundo a avaliaçáo dos professores, presente nos relatórios analisados - ou que, na prática, os principais objetivos são outros. A Tabela 4 reforça esse indício quanto aos "objetivos práticos". Como podemos ver, das atividades previstas como extracurriculares, o indicador "Atividades que desenvolvam a interaçáo e cooperaçáo entre as crianças" aparece com apenas uma ocorrência entre as atividades realizadas.

Sabemos que as demais dimensóes do esporte necessitam de processo de ensino-aprendizagem que considere conteúdos pertinentes aos aspectos técnicos relevantes para as práticas, seja no aspecto do alto rendimento, educacional, participaçáo, visto que, no primeiro, a obviedade é clara na busca da performance. Quanto ao esporte educacional, o ensino dos aspectos técnicos está presente em documentos próprios, como os Parâmetros Curriculares Nacionais (BRASIL, 1997, 1998), uma vez que o ensino é contextualizado em uma perspectiva de cultura corporal do movimento. Já quanto ao esporte de participação, as diversas propostas também orientam o ensino dos aspectos 
técnicos necessários ao divertir-se, como vemos, por exemplo, nas diretrizes do Programa Esporte e Lazer da Cidade (PELC) ${ }^{13}$. No entanto, se acontece o desencontro entre o prescrito no documento orientador, e o prescrito nos planejamentos cotidianos e nos relatos de atividades realizadas, acreditamos nas evidências de aproximação do ensino orientado conforme a tradição da educação física brasileira, isto é, por uma matriz hegemonicamente próxima do esporte de alto rendimento, assim como discutido por Bracht (1997), Oliveira (2005), Melo (2005) e outros.

Diante desses pequenos comentários, parece-nos evidente que o PCF apresenta uma relação perversa com a dimensão de esporte educacional. Perversa no sentido de que, ao mesmo tempo em que percebemos o destaque conferido ao esporte educacional no documento prescrito do projeto, assim como no site da Sesport, percebemos, outrossim, a forte ligação com o esporte de rendimento materializada na avaliação mensal realizada pelos professores.

Conforme exposto, não estamos desautorizando as práticas implementadas no PCF por se aproximarem da intencionalidade voltada ao esporte de alto rendimento. Concordamos com Bracht (1997), Oliveira (2005) e Melo (2005), ao evidenciarem que até mesmo o esporte educacional pode estar ligado à dimensão de rendimento. É o que parece acontecer na implementação do PCF. Acreditamos, também, na possibilidade de desencontros de visóes, isto é, enquanto os convênios parecem apresentar satisfação com os equipamentos, como demonstrado na Tabela 1, pode ocorrer que exista subversão nas práticas. Defendemos que, apesar de não haver um espaço demarcado segundo as normativas das modalidades, ainda assim as atividades são desenvolvidas na perspectiva do esporte de rendimento e não necessariamente com as adaptaçóes pretendidas pelas concepçóes do esporte educacional. E esse argumento nos faz lembrar as contribuiçóes de Marcellino (2001), para o qual o sucesso de uma PPEL depende da concepçáo dos gestores sobre o objeto da política, nesse caso, o esporte.

Prescritivamente, vemos uma concepção voltada para o esporte educacional, embora os indícios indiquem que a concepçáo não seja efetivamente essa. Mas, admitindo-se que sim, a desconexáo com o que acontece na ponta

13 Disponivel em: <http://www.esporte.gov.br/arquivos/snelis/esporteLazer/diretrizesPELCEdital20 I3.pdf>. 
do processo pode ser explicada por problemas com a formação do pessoal, o segundo aspecto apontado por Marcellino (2001). Se a formação inicial ou continuada dos agentes náo consegue efetivar o projeto na perspectiva do que está prescrito, então a desconexão é amplamente explicada. Não temos informação se o treinamento do pessoal, previsto no documento do PCF como responsabilidade da Sesport, tem efetivamente acontecido no sentido de solucionar esse problema.

\subsection{Aproximação da caracterização como ação intersetorial}

O modelo de gestão com açóes centralizadas e verticalizadas, predominante no Brasil até a década de 1970 do século passado, começou a se modificar a partir dos anos seguintes, já na década de 1980. Segundo Junqueira (2005), isso de deve ao processo de transformação no cenário político nacional, mas também pela influência da conjuntura internacional em crise do estado de bem-estar social nos países centrais.

Descentralizar, para Ckagnazaroff e Mota (2003), é delegar competências e recursos a organismos intermediários para que eles possam desenvolver suas respectivas gestóes de uma maneira mais eficiente, eficaz e com efetividade social, estando mais perto do cidadão e dos grupos sociais. Para Junqueira (2004), descentralização significa deslocamento do poder de decisão e transferência da gestão das políticas sociais, tendo como objetivo a garantia dos direitos sociais, democratizando a gestão. Isso, segundo o autor, ocorre por meio da

[...] da participação, apontando para a redefinição da relação Estado e Sociedade. A descentralização passa a constituir um fator importante para estimular a dinâmica participativa, mediante a abertura de canais de comunicação entre os usuários e as organizações descentralizadas, permitindo que os primeiros façam chegar suas necessidades a quem tem 0 poder de decidir. (JUNQUEIRA, 2004, p. 32).

Os estudos de Guimarães (2002) acenaram que não é tão clara a descentralização no Brasil. Segundo o autor, isso ocorre porque a tradição brasileira, em termos de gestáo, tem a marca da centralizaçáo e do gerenciamento. Contudo, a Constituiçáo de 1988 contribuiu bastante para a mudança de orientaçáo nos modelos de gestáo, inclusive pelo aceno concreto por meio dos artigos 194 e 204, os quais apresentam a descentralizaçáo participativa como necessária para garantir à área da seguridade social (saúde, previdência e 
assistência social) a gestão adequada para sua implantação e seu desenvolvimento (BRASIL, 1988). Foi esse direcionamento que permitiu o modelo de gestão descentralizada que foi aplicado ao Sistema Único de Saúde (SUS), dividindo responsabilidades entre as três esferas do governo: federal, estadual e municipal (JUNQUEIRA, 2004).

No entanto, a conquista da descentralização não resultou totalmente em gestão democrática, porque muitas vezes esse mecanismo é usado para que determinada instância deixe de cumprir suas responsabilidades, atribuindo estas a outros, ou mesmo sobrecarregando determinadas instâncias, como ocorre, por exemplo, com a distribuiçáo de responsabilidades entre as três esferas de governo. Até o efetivo envolvimento dos cidadáos no processo de descentralização, é necessária uma trajetória náo simples e não sem dificuldades, por motivos que já mencionamos. Por isso, a própria política de descentralização deve primar pela construçáo da cidadania (direitos), por meio de um processo de educação cidadã para a consciência e a participação corresponsável (JUNQUEIRA, 1997).

Quanto à intersetorialidade, Marcellino (2001) defende que ela é um dos três elementos básicos para se avaliar o bom funcionamento de uma Política Pública de Esporte e Lazer ${ }^{14}$.

Junqueira, Inojosa e Komatsu (1997) já diziam que os conceitos de descentralizaçáo e intersetorialidade se aproximam, uma vez que ambos têm como característica a prestação de serviços junto à administração pública de maneira a evitar as barreiras burocráticas. Além disso, em ambos, a ideia de participaçáo do cidadáo nas decisóes e açóes é primordial. No entanto, a diferença central está na natureza operacional dos conceitos, isto é, enquanto a descentralização opera com a transferência do poder de decisão para as instâncias mais periféricas, a intersetorialidade opera com a integração de decisóes a açóes de modo a atender as necessidades e expectativas sociais.

Embora, assim como a descentralização, a intersetorialidade tenha surgido a partir das contribuiçóes do setor privado, e esteja presente no Brasil nos discursos contemporâneos de gestão em geral, é no campo da política social

14 Os três elementos básicos apresentados por Marcellino (200I) são: a concepção de lazer dos gestores, a formação do pessoal e a intersetorialidade. 
que mais encontra eco. Isso se deve, mais uma vez em processo semelhante à descentralização, ao desenvolvimento do conceito no âmbito da saúde, e de como se passou a entender saúde em sentido ampliado. Nesse sentido, a saúde envolve diferentes dimensóes e necessidades do sujeito, implicando a ação de diferentes setores administrativos integrados (ANDRADE, 2006).

Considerando nossos últimos argumentos, acreditamos que a intersetorialidade auxilia na promoção, no desenvolvimento e na inclusáo social, quando opera com políticas integradas. No entanto, é difícil conceber a intersetorialidade desconectada da ideia de descentralização e, então, concordando com Junqueira, Inojosa e Komatsu (1997), podemos afirmar que a descentralização possibilita que a intersetorialidade promova a inclusão social. Por isso, esses autores afirmam que a junção dos dois conceitos constitui o novo paradigma para uma gestão pública que aperfeiçoe as funçôes do Estado.

Da forma como estamos apresentando, a intersetorialidade se mostra como uma estratégia política democrática que impacta diretamente as estruturas de poder, e isso não se dá sem conflitos e sem um tempo necessário à adaptação. $\mathrm{O}$ tempo será o suficiente para que se possa perceber a articulação de saberes e experiências entre cidadáos e instituiçóes públicas e privadas no planejamento, execução e avaliação de açóes políticas, que conduzam ao desenvolvimento da sociedade e inclusão social em processo de cogestáo. Assim operada, trata-se de uma estratégia de gestáo que possibilite a reversão do quadro de exclusão social, ao mesmo tempo em que promove melhorias na qualidade de vida da população e sepulta não somente a fragmentação das políticas, como a própria forma de se fazer política (JUNQUEIRA; INOJOSA, 1997; JUNQUEIRA; INOJOSA; KOMATSU, 1997).

Destacamos que, uma vez introduzida na gestão pública, o recurso à intersetorialidade não copia exclusivamente o interesse próprio de sua origem no âmbito privado, isto é, ganho econômico e atendimento de necessidades. Atrelados ao desenvolvimento econômico estão os desenvolvimentos político e social, necessários à autonomia dos sujeitos. Portanto, as açóes coletivas e democráticas se constituem como busca de soluçôes de problemas comuns e redução de desigualdades, o que dá a cada cidadáo o papel de protagonista no processo.

Do ponto de vista operacional, Farah (2000) afirma que há modelos de relação entre as instâncias quando se aplica a intersetorialidade no âmbito das 
esferas de governo. Segundo o autor, há articulação intergovernamental vertical, quando a relação ocorre entre as instâncias federal, estadual e municipal. Quando a relação é entre instituiçóes públicas da mesma instância, ocorre articulação horizontal. A articulação intersetorial, propriamente dita, se efetiva mediante processos completos de elaboração, implementação e avaliação de políticas públicas, de forma descentralizada e integrada com a sociedade civil inclusive. Desse modo, as formas de articulação vertical e horizontal, embora sejam níveis simplificados de intersetorialidade, constituem-se como perda de potencialidade para a efetivação da estratégia, se as relaçóes de troca de favores permanecerem entre as instâncias.

Em termos de educação política, nunca é demais lembrarmos que a participaçáo da sociedade civil, em todas as etapas do processo em que as açóes intersetoriais acontecem, remete para a participação nos espaços de decisão política e náo apenas de consumo e assistência das políticas oferecidas em pacotes.

Diante do exposto, Junqueira $(1997,2004,2005)$ considera a descentralização e a intersetorialidade como novas estratégias de gestão a fim de melhorar a qualidade de vida dos cidadãos, os quais, a partir de então, são considerados sujeitos de direito, ativos no processo de implementação das políticas.

Assim, a questão sobre a qual passaremos a discorrer é o alcance da intersetorialidade no PCF, tendo em vista sua importância no processo de sistematização de uma gestão democrática, ao lado de indicadores tais como eficiência, eficácia e efetividade social.

Eficiência, eficácia e efetividade são três importantes elementos de uma avaliação de políticas públicas. A eficiência refere-se ao processo, à relação entre custo e benefício de uma açáo realizada, visando ao melhor aproveitamento dos recursos (menor recurso, maior resultado). A eficácia, por sua vez, refere-se aos resultados efetivamente alcançados (metas atingidas) - está relacionada ao planejamento da política pública e sua real aplicação - o que não significa que se restringe à avaliaçáo dos resultados parciais, mas sim, analisa o que fora planejado e o que foi realmente atingido, buscando sempre a maximizaçáo dos rendimentos das açóes. Já a efetividade social diz respeito ao impacto da política pública na vida dos cidadáos; analisa as mudanças ocorridas na sociedade após sua efetivaçáo, sempre avaliando os resultados econômicos e sociais da política pública (BELLONI; MAGALHĀES; SOUZA, 2007). 
Embora esse modelo de avaliação nos indique interessantes ferramentas de aperfeiçoamento de políticas públicas, ele não é suficiente, pois, como argumenta Paula (2005), trata-se de um modelo gerencial, em nível Governamental, o que não induz a participação da sociedade civil. Logo, ao visarmos ao aprofundamento democrático a partir da participação civil, é necessário extrapolarmos o modelo gerencial - este que, segundo Paula (2005), enfatiza os resultados em termos de metas -, e acrescentarmos a participação ao processo de elaboração, implementação e avaliação de políticas públicas. Nessa perspectiva que desloca os principais critérios do processo de execuçáo de políticas públicas - que é, também, um deslocamento de sentidos - a noção de cidadania também é aprofundada, por meio do sentido de eficácia política que é gerado pela participação no processo de decisão (PATEMAN, 1992).

Para tratarmos das aproximaçóes e dos distanciamentos do PCF à dimensão de intersetorialidade, categoria apresentada como determinante de uma gestáo simultaneamente democrática e inovadora, precisamos tomar novamente os documentos acessados para esse estudo com um esforço analítico.

No Projeto Prescrito, encontramos algumas pistas na seção referente às "responsabilidades dos convenentes". Lá, encontramos que as coordenaçóes locais são responsáveis por colher:

[...] depoimentos escritos referentes ao Projeto Campeões de Futuro, de pais, alunos, professores e outros. Sempre que ocorrer este tipo de manifestação, enviar o original à Coordenação Geral (Projeto Campeões de Futuro) da Secretaria de Estado de Esporte e Lazer; realizar contatos com as associações de moradores, escolas, unidades de saúde, outros; divulgar junto aos movimentos organizadores do projeto com apresentação das alternativas de projeto com participantes, pais ou responsáveis; avaliar com as comunidades e com as equipes técnicas os trabalhos desenvolvidos; apresentar as propostas da comunidade para a continuidade dos trabalhos; realizar reuniões com pais ou responsáveis. (SECRETARIA DE ESTADO DE ESPORTE E LAZER, [s. d.] [a], [s. p.]).

O conjunto de responsabilidades mencionadas demonstra a prescrição por uma iniciativa descentralizada, e que envolva diversos atores sociais para além da estrutura administrativa existente entre as partes que fazem o convênio formal. Parece uma iniciativa interessante, embora se ressinta de divisão equitativa de responsabilidades entre as partes quanto ao desenvolvimento dessas tarefas.

Quando falamos em divisão equitativa de responsabilidades, estamos situando a participação no PCF dentro dos limites do que seria realmente responsabilidade da 
sociedade civil e não do Estado. Com isso, estamos argumentando em favor de uma participação social que não confunda a sociedade civil com o Estado (HABERMAS, 2003), isto é, que não resulte em engessamento das instituições da sociedade civil em estruturas formalizadas demais ou burocratizadas, ou mesmo que resulte em atribuição de poderes administrativos estritamente pertencentes ao Estado, aos atores sociais pertencentes à sociedade civil (AVRITZER; COSTA, 2004).

Portanto, é possível a participação efetiva em todas as etapas de implementação de uma política pública por meio de contrapartidas estabelecidas nos instrumentos de convênio, o que pode se constituir como um canal de participação diferenciado entre as esferas pública e política, estabelecendo a periodicidade, as competências, os deveres, e por que não afirmar, os direitos de cada parte em todo o processo de implementação da política pública (GOHN, 2003).

A despeito das possibilidades de participação potencializadas pelas afirmaçóes anteriores, também existe a possibilidade de participação por meio do exercício do controle social, o qual náo se nota no Projeto Prescrito, pelo menos do ponto de vista formal, da forma aqui tratada.

A ideia mais próxima de controle social identificada no Projeto Prescrito seria a da atuação das federaçôes esportivas. Uma federação teria o papel de "Supervisora técnica do projeto" (SECRETARIA DE ESTADO DE ESPORTE E LAZER, [s. d.] [a], [s. p.]). Essa tarefa da supervisionar, além de gerar dificuldades operacionais pelo fato de as federaçóes não participarem do Protocolo de Intençôes ${ }^{15}$ entre as partes convenentes, não parece suprir as dimensóes que envolvem o projeto, principalmente quanto ao controle social sobre os gastos públicos, papel que poderia ser realizado, por exemplo, pelo Conselho Estadual de Esporte ${ }^{16}$, embora esse órgão exista no Estado apenas com funções consultivas.

Todas as atribuiçóes previstas para as entidades convenentes no Projeto Prescrito aparecem em um único item no Protocolo de Intenções firmado entre as partes conveniadas. Nesse documento, encontramos entre as responsabilidades

15 Trata-se de um documento por meio do qual a Sesport e a prefeitura solicitante firmam o convênio para a implementação do Programa. Tem o formato de um contrato entre as partes, onde ficam explicitadas as responsabilidades e direitos de cada parte. Nesse texto o documento será designado como SECRETARIA DE ESTADO DE ESPORTE E LAZER, [s. d.] [b], [s. p.]. Da mesma forma que o documento orientador, também não referenciaremos ano de publicação e página. Conferir a nota de rodapé 7.

I6 O Conselho Estadual de Esporte foi instituido pela Lei Complementar n³22, publicada no Diário Oficial dos Poderes do Estado no dia 19 de maio de 2005. 
do convenente, no item 3.2.3, que a gestáo local do setor de esporte e lazer deve: "Mobilizar a integração entre os Secretários Municipais da área geral (Saúde, Educação, Meio-Ambiente, Cultura, Açáo Social, Cidadania, entre outros) para acompanhamento e garantia dos serviços a crianças e adolescentes do Projeto" (SECRETARIA DE ESTADO DE ESPORTE E LAZER, [s. d.] [b], [s. p.]). Essa parece ser uma indicação importante para a intersetorialidade, apesar de não termos evidências de que tal integração entre setores aconteça no nível da gestáo do setor no governo do Estado, isto é, entre a Sesport e as demais secretarias.

Como mencionamos, apesar das potencialidades positivas apontadas nos documentos, não temos nenhuma evidência da efetivação de açóes intersetoriais no PCF na forma como foi discutida nas referências por nós apresentadas, porque os relatórios acessados que informam o funcionamento do programa não trazem informaçóes sobre essa dimensão do funcionamento. Da mesma maneira, não temos evidência de que esse aspecto seja monitorado pela coordenaçáo do programa, uma vez que o quantitativo de documentos que nos foi disponibilizado quanto às informaçóes das açóes realizadas náo se constitui em um bom sinal de monitoramento.

Sem condições de monitoramento adequado e sem controle social, resta à coordenação do programa confiar na dimensão ética das pessoas físicas vinculadas aos convênios. No entanto, em se tratando de ação política, há de se considerar que não é uma das possibilidades mais seguras. Óbvio que, do ponto de vista da política pública, a situação do monitoramento é condição não somente para fins de avaliação, mas, sobretudo, para efetivação da intersetorialidade como estratégia de gestão e alcance de objetivos.

As reflexões apontadas nos parágrafos anteriores nos permitem observar que o PCF necessita passar por dois processos complementares: a descentralização, discorrida por Ckagnazaroff e Mota (2003); e a intersetorialidade, discorrida por Junqueira $(1997,2004,2005)$ e por nós defendida com o incremento da participação da sociedade civil nos processos de decisão. Quanto à descentralização, percebemos que existem predisposições no Projeto Prescrito, mas não há operacionalização concreta nos demais documentos, uma vez que se observam prescrições de responsabilidades que não são todas replicadas entre os documentos. Além disso, precisaria ficar mais claro um mecanismo de monitoramento do cumprimento das funçóes de cada parte. Nesse sentido, não observamos esse tipo de perspectiva nos diversos formulários de avaliação e monitoramento disponibilizados no site 
da Sesport. Da mesma forma, não encontramos documentos que informassem melhor desenvolvimento do sistema de monitoramento do PCF quanto aos aspectos aqui mencionados.

No que se refere à intersetorialidade, náo encontramos documentos que nos informassem os mecanismos de articulação entre os diversos órgãos do Poder Público, assim como deste com a sociedade civil. $\mathrm{O}$ único documento firmado é o Protocolo de Intençóes. Não encontramos um documento que se caracterizasse como uma Proposta Político Pedagógica, já que se trata de uma iniciativa anunciada como esporte educacional; nem encontramos um documento que se caracterizasse como um plano de formação dos agentes, o que, aliás, está prescrito como responsabilidade da Sesport. Outrossim, não encontramos, em nenhum documento, indicativo de participação de outros órgáos do Poder Público ou da sociedade civil em todas as etapas do processo de implementação da política pública, da elaboração à avaliação.

Portanto, as potencialidades do PCF como uma política descentralizada, intersetorial, participativa e de garantia do acesso ao esporte como direito parecem evidentes em nível da prescrição e até mesmo em poucos documentos que informam o funcionamento do programa. No entanto, ainda vemos, na grande maioria desses documentos que informam o funcionamento do programa, que o PCF está longe de se caracterizar como uma política pública no melhor sentido do conceito. Uma possibilidade de aumentar essas certezas, mas também de desconstruí-las, pode ser o estudo do cotidiano do programa junto aos atores sociais que atuam na ponta do processo, inseridos no campo de efetivaçáo do programa.

\section{Considerações finais}

A partir das análises e interpretaçóes dos dados apresentados nesse estudo, concluímos que há informaçóes sobre o PCF que o aproximam de uma concepçáo de esporte realizado na perspectiva educacional, informaçóes encontradas tanto no Projeto Prescrito quanto no Protocolo de Intençôes firmado entre as partes. As aproximaçóes também são percebidas nas informaçôes coletadas nos documentos que informam sobre o funcionamento do PCF, entre as quais destacamos o nível de satisfaçáo dos agentes locais com os equipamentos utilizados para as práticas. Como esses equipamentos não são caracterizados como "oficiais" em termos de medidas, inferimos que há uma tendência de os agentes promoverem adaptaçóes das atividades, o que aproximaria o 
programa das perspectivas não só do esporte educacional, como também do esporte de participação. No entanto, não desconsideramos a realidade da maior parte das cidades do interior que náo possuem espaços oficiais para as práticas esportivas, quer seja no Brasil quer seja no Espírito Santo.

Além disso, contrariando as expectativas, nos documentos coletados que informam sobre as atividades desenvolvidas nos núcleos, encontramos bastante destaque para a realização de práticas que aproximam as atividades da perspectiva do esporte de rendimento. Em destaque, podemos citar a ênfase no ensino das regras e técnicas dos esportes, assim como nos elementos do condicionamento físico. Em sentido contrário, há pouca ênfase nos mesmos documentos tomados de informaçóes dos agentes, a respeito do desenvolvimento de atividades "extraclasse", ou mesmo de atividades de interação e desenvolvimento de sociabilidades.

Verificamos que o programa está inserido em um plano governamental maior, denominado de ES-2025. Também devemos assinalar que, quando observamos as aproximaçóes do PCF à dimensão de política pública, observamos algo parecido ao que mencionamos antes, isto é, existem informações que aproximam e distanciam o programa de uma política pública eficiente, eficaz e efetiva. No documento prescrito, encontramos dados que nos permitem considerar o PCF como uma política acessível náo somente às entidades que se interessem em realizar convênio, como também a toda uma população do Estado na faixa etária entre sete e 17 anos. No entanto, há evidências, baseadas, sobretudo, nessa última informação, que indicam a focalização do programa.

Por fim, no que diz respeito à identificaçáo do PCF com a caracterizaçáo de uma política intersetorial, nossas descobertas iniciais encontradas tanto no Projeto Prescrito quanto no Protocolo de Intençóes são opostas às encontradas nos tópicos anteriores, isto é, as informaçóes apontavam para uma boa possibilidade de articulaçáo entre os entes conveniados. No entanto, em todos os documentos, percebemos a ausência de alguns elementos essenciais para a caracterização da política como intersetorial, entre os quais destacamos:

a) Os documentos não preveem a participaçáo da sociedade civil em todas as etapas do processo de implementação da política, seja nos convênios firmados entre órgãos do Estado, seja nos convênios firmados entre o Estado e a sociedade civil. 
b) Não encontramos informaçóes quanto aos procedimentos de controle social, algo importante para caracterizar o bom funcionamento da política pública.

c) A Sesport firma convênios com entidades do setor público, privado e da sociedade civil, mas náo constitui os convênios como uma rede. Nesse caso, parecem se constituir iniciativas estanques e isoladas, que não permitem a interação entre diferentes experiências.

Em termos gerais, podemos retomar Marcellino (2001) para elucidar que o bom funcionamento de uma política pública de esporte e lazer depende da concepção dos gestores sobre o objeto da política, a formaçáo do quadro de pessoal para atuar nas políticas e da intersetorialidade das açóes.

Por fim, ressaltamos que, especificamente quanto à intersetorialidade, aqui abordada - mais ainda no que diz respeito às relaçóes entre os diferentes setores da gestão e desses com a sociedade civil - não se trata de dividir o "trabalho" do Estado com a sociedade civil. Isso reduziria a dimensão do Estado e as suas responsabilidades, transferindo-as para as instituiçóes da sociedade civil. Sabe-se que a formulação, implementação e avaliação das Políticas Públicas de Esporte e Lazer (PPEL's) são de responsabilidade dos aparelhos de Estado, o que não fecha as possibilidades de uma gestão mais democrática, abrindo espaços para maior participaçáo da sociedade civil em uma gestáo participativa. O que defendemos é a abertura de canais que favoreçam o diálogo entre a esfera pública e a esfera política, bem como a maior participação social nas tomadas de decisóes. Dessa forma, aumentarão as possibilidades de ações políticas mais eficazes, e a democracia poderá ser fortalecida mediante a participação da sociedade civil, permitindo que haja mais conquistas sociais.

\section{Referências}

ANDRADE, L. O. M. A saúde e o dilema da intersetorialidade. São Paulo: Hucitec, 2006.

AVRITZER, L.; COSTA, S. Teoria Crítica, Democracia e Esfera Pública: Concepções e Usos na América Latina. DADOS - Revista de Ciências Sociais, Rio de Janeiro, v. 47, n. 4, 2004, p. $703-728$. Disponível em: <http://www.scielo.br/pdf/dados/v47n4/a03v47n4.pdf>. Acesso em: 27 abr. 2014.

AZEVEDO, A. C. B. Esporte, Ensino e Educação Física. In: MALINA, A.; CESARIO, S. (Org.). Esporte: fator de integração e inclusão social? Campo Grande: UFMS, 2009. p. 71-85. 
BELlONI, I.; MAGAlHÃES, H.; SOUZA, L. C. Metodologia de Avaliaçáo em Políticas Públicas. 4. ed. São Paulo: Cortez, 2007.

BEHRING, E. R.; BOSCHETTI, I. Política social: fundamentos e história. 5. ed. São Paulo: Cortez, 2008.

BRASIL. Constituiçâoo (1988). Constituição da República Federativa do Brasil de 1988. Disponível em: <http://www.planalto.gov.br/ccivil_03/constituicao/constituicao.htm>. Acesso em: 25 abr. 2014.

MINISTÉRIO DA EDUCAÇÃO. Secretaria de Educação Fundamental. Parâmetros Curriculares Nacionais: $1^{\text {a }}$ a $4^{\text {a }}$ série. Brasília: SEF/MEC, v. 7, 1997.

MINISTÉRIO DA EDUCAÇÃO. Secretaria de Educação Fundamental. Parâmetros Curriculares Nacionais de Educaçáo Física: $3^{\circ}$ e $4^{\circ}$ ciclos do Ensino Fundamental. Brasília: SEF/ MEC, 1998.

- MINISTÉRIO DO ESPORTE. Programa Esporte e Lazer da Cidade PELC. Orientações para implantação. Diretrizes - Edital 2013. Brasília, 2013. Disponível em: <http:// www.esporte.gov.br/arquivos/snelis/esporteLazer/diretrizesPELCEdital2013.pdf>. Acesso em: 4 mar. 2014.

BUENO, L. Políticas públicas do esporte no Brasil: razóes para o predomínio do alto rendimento. 2008. 200f. Tese (Doutorado em Administração) - Escola de Administração de Empresas de São Paulo, Fundação Getúlio Vargas, Rio de Janeiro: FGV, 2008.

CKAGNAZAROFF, I. B.; MOTA, N. R. Consideraçóes sobre a relação entre descentralização e intersetorialidade como estratégias de modernização de prefeituras municipais. Economia \& Gestáo - PUC Minas, Belo Horizonte, v. 3, n. 6, p. 23-41, 2013. Disponível em: <http:// periodicos.pucminas.br/index.php/economiaegestao/article/view/94>. Acesso em: 27 abr. 2014.

FALEIROS, V. de P. O que é Política social. 3. ed. São Paulo: Editora Brasiliense, 1988.

FARAH, M. F. S. Parcerias, Novos Arranjos Institucionais e Políticas Públicas Locais. Cadernos Gestáo Pública e Cidadania, v. 18, abr. 2000. Disponível em: <http://ceapg.fgv.br/sites/ceapg.fgv. br/files/file/Cadernos/Cad18.pdf>. Acesso em: 27 abr. 2014.

FREITAS, F. M. de C. Esporte em democracia: a gênese do político. In: MALINA, A.; CESARIO, S. (Org.). Esporte: fator de integração e inclusão social? Campo Grande: UFMS, 2009. [s. p.]

GOHN, M. da G. Conselhos Gestores e participaçáo sociopolítica. 2. ed. São Paulo: Cortez, 2003. GOVERNO DO ESPÍRITO SANTO. Plano de Desenvolvimento Espírito Santo 2025 Cenários Exploratórios para o Espírito Santo no Horizonte 2006-2025. Vitória: Macroplan, 2006. 
GUIMARÁES, M. C. L. O debate sobre a descentralização de políticas públicas: um balanço bibliográfico. O\&S - Organizaçôes \& Sociedade, Salvador, v. 9, n. 23, p. 57-77, set./dez. 2002.

HABERMAS, J. Direito e Democracia: entre facticidade e validade. Volume II. 2. ed. Rio de Janeiro: Tempo Brasileiro, 2003.

INSTITUTO BRASILEIRO DE GEOGRAFIA E ESTATÍSTICA (IBGE). Perfil dos Municípios Brasileiros: Esporte 2003. Rio de Janeiro: IBGE, 2006. Disponível em: <http://www.ibge.gov.br/ home/estatistica/economia/perfilmunic/esporte2003/esporte2003.pdf>. Acesso em: 27 abr. 2014.

JUNQUEIRA, L. A. P. A gestão intersetorial das políticas sociais e o terceiro setor. Saúde e Sociedade, v. 13, n. 1, p. 25-36, jan./abr. 2004. Disponível em: <http://www.revistas.usp.br/ sausoc/article/viewFile/7105/8577>. Acesso em: 28 abr. 2014.

. Articulaçóes entre o serviço público e o cidadão. In: CONGRESO INTERNACIONAL DEL CLAD SOBRE LA REFORMA DEL ESTADO Y DE LA ADMINISTRACIÓN PÚBLICA, 10., Santiago, Chile, p. 18-21, oct. 2005.

- Novas formas de gestão na saúde: descentralização e intersetorialidade. Saúde e Sociedade v. 6, n. 2, p. 31-46, 1997. Disponível em: <http://www.scielo.br/pdf/sausoc/v6n2/05.pdf>. Acesso em: 28 abr. 2014.

JUNQUEIRA, L. A. P.; INOJOSA, R. M. Desenvolvimento social e intersetorialidade: a cidade solidária. São Paulo: FUNDAP, 1997.

JUNQUEIRA, L. A. P.; INOJOSA, R. M.; KOMATSU, S. Descentralização e intersetorialidade na Gestão Pública Municipal no Brasil: a experiência de Fortaleza. In: XI Concurso de Ensayos del CLAD "El tránsito de la cultura burocrática al modelo de la gerencia pública: Perspectivas, Posibilidades y Limitaciones". Caracas: Unesco/CLAD, 1997. p. 63-124.

MANHÁES, E. D. Políticas de Esporte no Brasil. 2. ed. Rio de Janeiro: Paz e Terra, 2002.

MARCELlinO, N. C. (Org.). Lazer e Esporte: Políticas Públicas. 2. ed. Campinas: Autores Associados, 2001.

MARINHO, A. Lazer, Aventura e Risco: reflexôes sobre atividades realizadas na natureza. Movimento, Porto Alegre, v. 14, n. 2, p. 181-206, maio/ago. 2008.

MARINHO, V. O esporte pode tudo. São Paulo: Cortez, 2010. - (Coleção questóes da nossa época; v. 3).

MASCARENHAS, F. Lazer como prática da liberdade: uma proposta educativa para a juventude. 2. ed. Goiana: UFG, 2004.

MELO, M. P. de. Esporte e Juventude Pobre: Políticas Públicas na Vila Olímpica da Maré. São Paulo: Autores Associados, 2005. 
OliveirA, A. A. B. de; PERIM, G. L. (Org.). Fundamentos Pedagógicos para o programa segundo tempo. Brasília: Ministério dos Esportes; Porto Alegre: UFRGS, 2008.

OLIVEIRA, S. A. de. Reinventando o esporte: possibilidades da prática pedagógica. 2. ed. Campinas: Autores Associados: Chancela editorial CBCE, 2005.

PATEMAN, C. Participaçáo e teoria democrática. Rio de Janeiro: Paz e Terra, 1992.

PAULA, A. P. P. de. Por uma nova gestáo pública. Rio de Janeiro: Editora FGV, 2005.

RICHARDSON, R. J.; PERES, J. A. de S. Pesquisa Social: Métodos e Técnicas. 3. ed. rev. Ampl. São Paulo: Atlas, 1999.

RITTNER, V. Esporte: um meio de integração social? In: MALINA, A.; CESARIO, S. (Org.). Esporte: fator de integração e inclusão social? Campo Grande: UFMS, 2009. p. 33-49.

SECRETARIA DE ESPORTE E LAZER (Sesport). Campeóes de Futuro: projeto de inclusão social pelo esporte. Vitória: Sesport, [s. d.] [a], [s. p.].

SECRETARIA DE ESTADO DE ESPORTE E LAZER (Sesport). Campeóes de Futuro: Protocolo de Intençóes. Vitória: Sesport, [s. d.] [b], [s. p.].

SENOS, J. Identidade social, auto-estima e resultados escolares. Análise Psicológica, v. 1, n. 5, p. 123-13, 1997. Disponível em: <http://www.scielo.oces.mctes.pt/pdf/aps/v15n1/v15n1a10. pdf>. Acesso em: 27 abr. 2014.

AREIAS, K. T. V et al. Perspectivas de Contribuição do Setor de Esporte e Lazer para o Desenvolvimento do Estado do Espírito Santo. In: ISAYAMA, H. F. et al. (Org.) Coletânea do XIII Seminário “O Lazer em Debate”. Belo Horizonte: UFMG/DEF/CELAR, 2012. p. 245-251 Disponível em: <https://bazar21.files.wordpress.com/2012/05/coletanea-lazer-em-debate-comcapa.pdf>. Acesso em: 4 mar. 2014.

TUBINO, M. J. G. Dimensóes sociais do esporte. 2. ed. São Paulo: Cortez, 2001.

VERONEZ, L. F. C. Quando o Estado joga a favor do Privado: as políticas de esporte após a Constituição Federal de 1988. 2005. Tese (Doutorado em Educação Física) - Programa de Pós-graduação em Educação Física, Universidade Estadual de Campinas, Campinas, SP: UNICAMP, 2005. 


\section{The intersectoriality in the public policies of sports and leisure: an analysis of the "Programa Campeões do Futuro"}

\section{Abstract}

The objective of this paper is to analyze the limits and potential of "Future Champions Program" (PCF) as a public policy intersectoral sports education. To do so, we analyze the prospects of intersectionality, decentralization and democracy in management, with a focus on civil society participation, based on analysis of documents collected in the State Department of Sport and Recreation of the Holy Spirit (Sesport) and its web site, as well as interviews with PCF coordination. The results show that the conception of sport in the PCF is differentiated between prescription and implementation. Likewise, we find the possibility of prescribing good articulation between the insured entities, features intersectionality, but we found no evidence of occurrences in the implementation.

Keywords: Public Policy. Sport. Leisure. Intersectionality. Participation. 